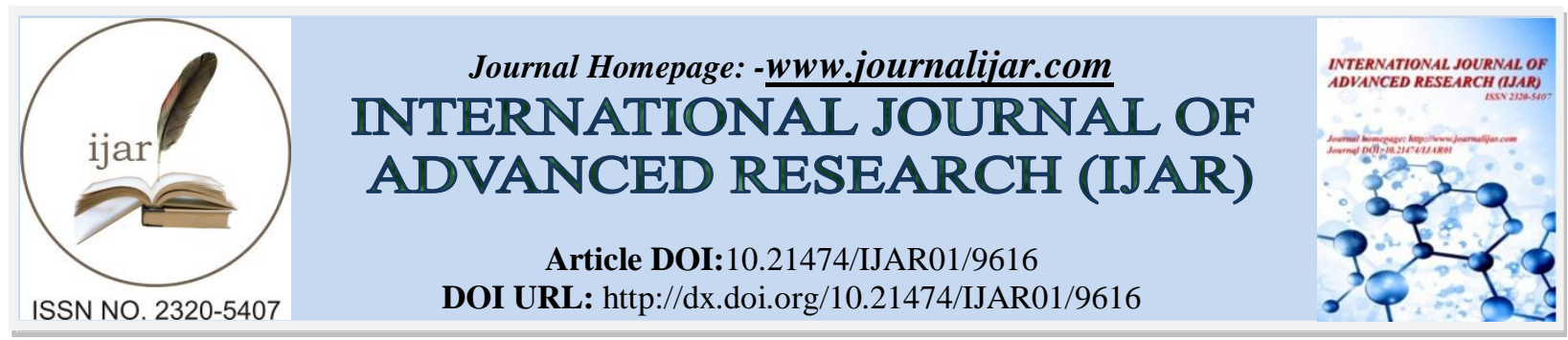

RESEARCH ARTICLE

\title{
EFFECTIVENESS OF ORAL SUCROSE SOLUTION ON PAIN PERCEPTION AMONG INFANTS RECEIVING IMMUNIZATION INJECTION IN ASHWIN HOSPITAL AT COIMBATORE.
}

\author{
Dr. K. Jeyabarathi and Ms. Arunima Mohan. \\ PPG college of Nursing Coimbatore.
}

\section{Manuscript Info}

Manuscript History

Received: 20 June 2019

Final Accepted: 22 July 2019

Published: August 2019

\section{Abstract}

Statement of the problem: Effectiveness of oral sucrose solution on pain perception among infants receiving immunization injection in Ashwin Hospital at Coimbatore.

Objectives: a) To assess the level of pain among infants receiving immunization after administering the oral sucrose solution. b) To assess the effectiveness of oral sucrose solution on pain perception among experimental group and control group infants. c) To find out the association between post test level of pain with selected demographic variables among experimental group infants. d) To find out the association between post test level of pain perception with selected demographic variables among control group infants.

Methodology: The research design used was Quasi Experimental Post test only Design. Sample size was 60 infants who was receiving immunization, in which 30 were in experimental group and 30 were in control group. The samples were selected by using convenient sampling method. NIPS pain scale was used for the data collection which was a standardized tool. The data collection tool was valued by four experts, reliability was established by Karl pearsons correlation method. The main study was conducted in Ashwin hospital at Coimbatore. The data collected were tabulated, analyzed and interpreted by using micro soft excel 2007.

Results:Inferential and descriptive statistics used to evaluate the effectiveness of the oral sucrose solution for pain perception among infants receiving immunization injection. Student $t$ test was used to find out significant difference between experimental and control group pain perception score. The ' $t$ ' test score was 19.54. $x^{2}$ used to assess the association between the experimental and control group with demographic variables of the infants. in experimental group after the sucrose administration majority 21 (70\%) of infants had mild pain, were as in control group majority $29(97 \%)$ of infants had severe pain. In experimental group there was no significant relationship between the demographic variables and sucrose solution on pain perception. In control group there was no significant relationship between the demographic variable and sucrose solution on pain perception. Conclusion:The findings of the study revealed that $24 \%$ sucrose administration among infants who are undergoing immunization was independently effective in reducing pain perception. 


\section{Introduction:-}

Childhood is a period of rapid growth and development. At no other time in life are physical changes and developmental achievements so dramatic as during infancy. In the early months baby's sense sharpens and, with the process of attachment to primary care givers, they form their first social relationships. Because of these rapid changes first year of life becomes a very crucial one. (Marilyn J et al. 2009).

Immunization is one of the most important preventive measures in children's lives, as it provides protection against the most dangerous childhood diseases. Pain is an unpleasant experience to all individual. Every individual experiencing pain needs care and warmth. Infants are more sensitive to pain than older children and adults because of their still in the process of development both physically and mentally. This is the reason that most of the children seek medical care. (David Wilson, 2009).

\section{Statement Of The Problem}

Effectiveness of oral sucrose solution on pain perception among infants receiving immunization injection in Ashwin hospital at Coimbatore.

\section{Objectives:-}

1. To assess the level of pain perception among infants receiving immunization after administering the oral sucrose solution.

2. To assess the effectiveness of oral sucrose solution on pain perception among experimental group and control group infants.

3. To find out the association between post test level of pain perception with selected demographic variables among experimental group infants.

4. To find out the association between post test level of pain perception with selected demographic variables among control group infants.

\section{Materials And Methods:-}

A quantitative evaluative research approach and quasi experimental post test only design was used for the study. Non probability convenient sampling technique was used to select the samples from the population of the study. The sample size for the study includes 60 infants in that 30 samples for experimental group and 30 samples for control group. Infants who satisfied the inclusion criteria were selected for the study. One sample for experimental and the other sample for control group, likewise the sample were assigned to both groups till the sample size reached.2 min before immunization $2 \mathrm{ml}$ oral sucrose solution was given to experimental group and then immunization given and pain was assessed by using NIPS and no intervention only routine comfort measures was given for control group.

\section{Results:-}

Distribution of Mean, Mean Difference, Standard Deviation and t value regarding post test pain perception.

\begin{tabular}{|c|c|c|c|c|}
\hline & & & & \\
\hline \multirow{2}{*}{ Effectiveness } & \multicolumn{3}{|c|}{ Post test } & \multirow{2}{*}{ 't' value } \\
\hline & Mean & M.D & S.D & \\
\hline $\begin{array}{l}\text { Experimental } \\
\text { group }\end{array}$ & 5.13 & \multirow[t]{2}{*}{6.07} & 1.43 & \multirow[t]{2}{*}{ 19.54* } \\
\hline Control group & 11.2 & & 0.89 & \\
\hline
\end{tabular}

\section{(*significant)}




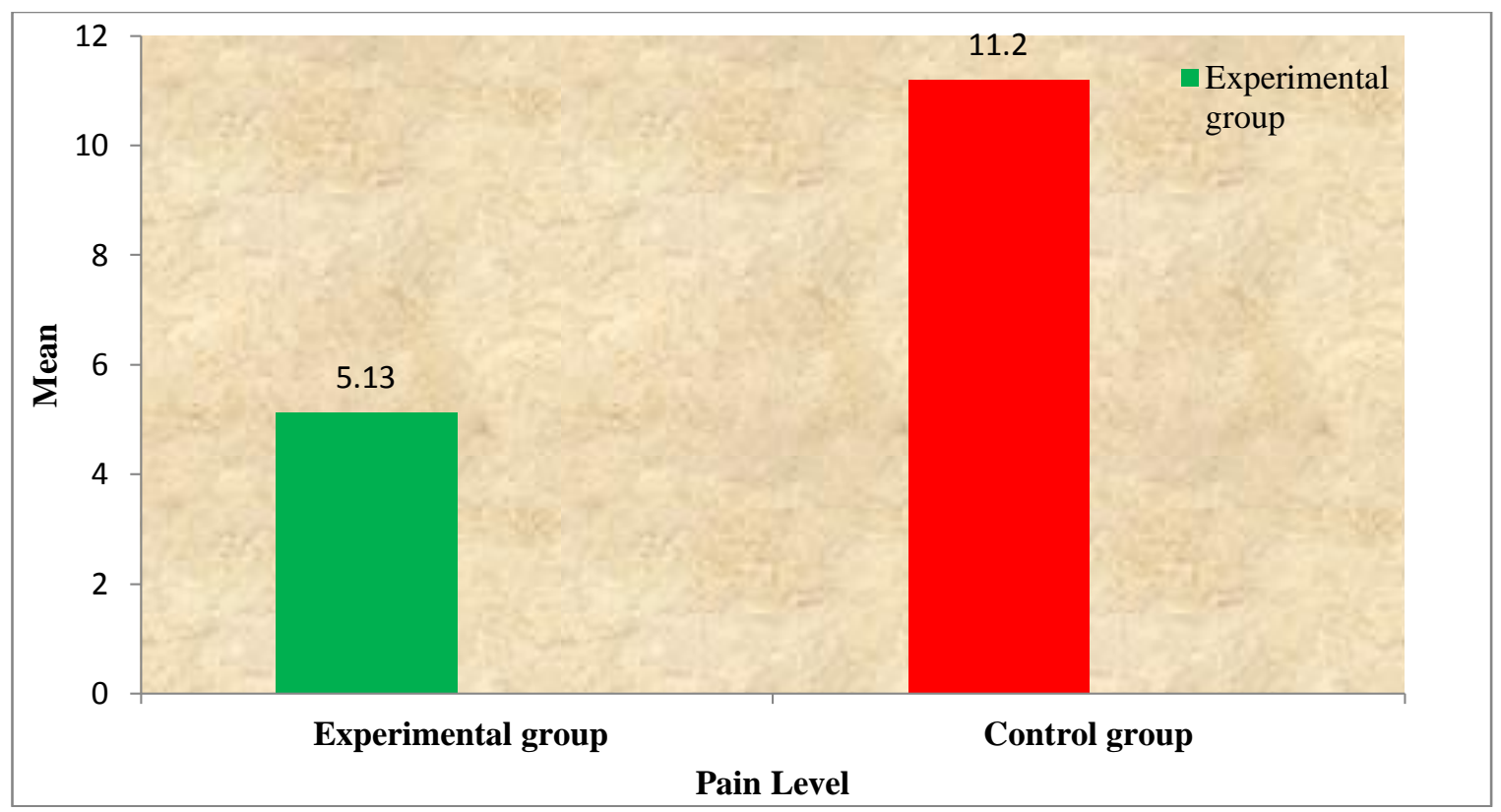

Figure 1:-Distribution of statistical value of post test score for experimental and control group regarding level of pain during vaccination among infants.

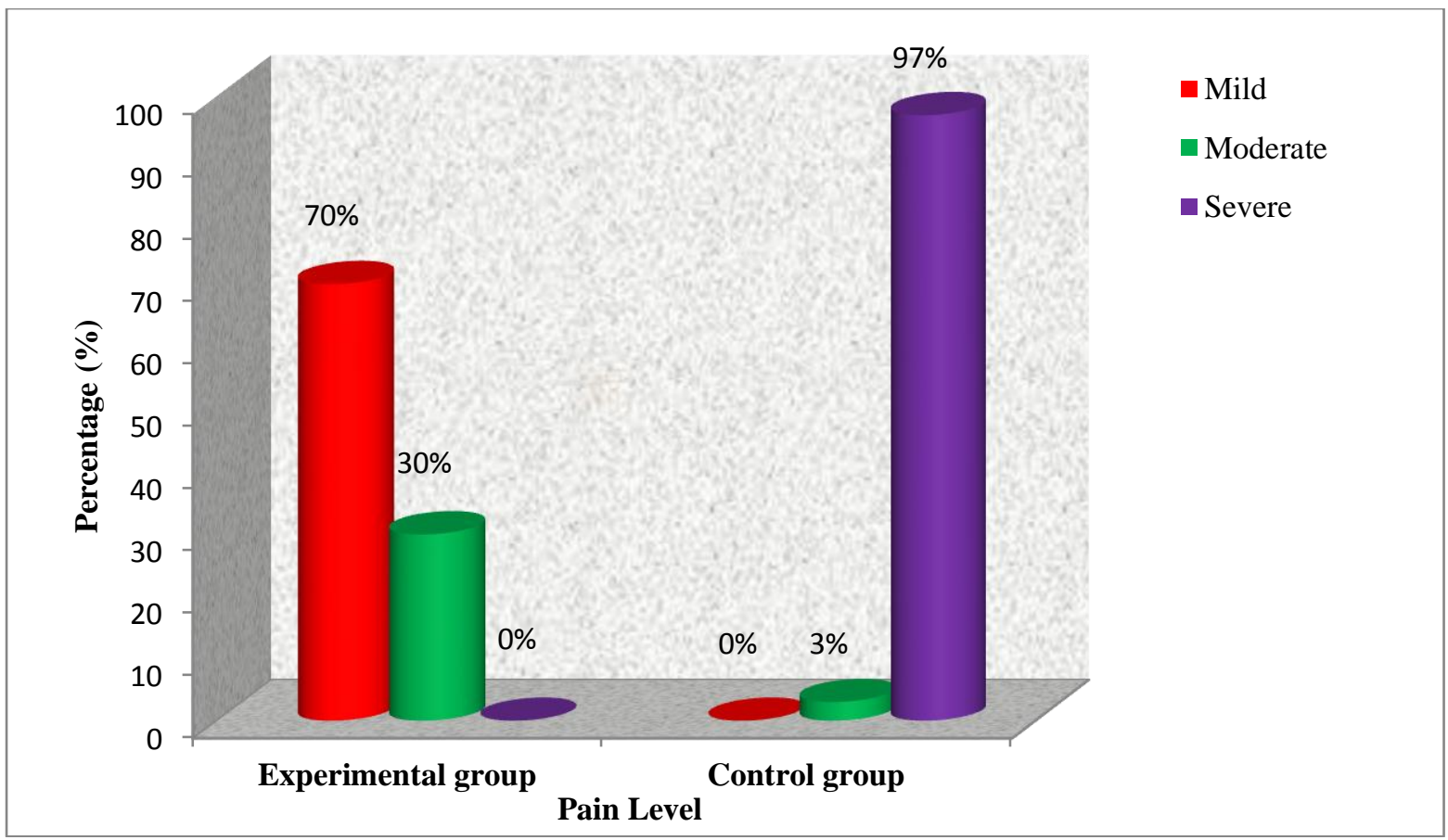

Figure 2:-Comparison of Pain Level in Experimental group and Control group according to Modified NIPS.

\section{Discussion:-}

The first objective of the study was to assess the level of pain among infants receiving immunization after administering the oral sucrose solution.

To infants in experimental group sucrose solution was administered 2 minutes prior to injection. Pain perception was assessed after the intervention while giving injection. Among experimental group the majority 20 infants (67\%) perceived mild pain and the least 10 infants (33\%) perceived moderate pain. No infant perceived severe pain after administering sucrose solution. Among control group the majority 29 infants (97\%) perceived severe pain and the 
least 1 infant (3\%) perceived moderate pain. It was inferred that the pain level was reduced after the administration of oral sucrose solution prior to injection among infants.

The second objective of the study was to assess the effectiveness of oral sucrose solution on pain perception in experimental group and control group infants.

The present study revealed the post test mean difference was 4.55 . The ' $t$ ' value 17.08 . The pain perception was comfortably less with oral sucrose solution than with usual procedure among infants. It could be inferred that sucrose solution prior to injection was effective in decreasing pain perception among infants.

The third objective of the study was to find out the association between post test level of pain with selected demographic variables among experimental group infants.

The association between the level of post test pain and their demographic variables like age $x^{2}=2.6$, gender $x^{2}=$ 1.42 ,education of father $x^{2}=3.79$, education of mother $x^{2}=1.4$, occupation of father $x^{2}=3.79$, occupation of mother $x^{2}=2.6$, income $x^{2}=2.13$, number of children $x^{2}=2.46$, birth order $x^{2}=2.46$, religion $x^{2}=0.08$, type of family $x^{2}=$ 1.11 , place of residence $x^{2}=1.42$, types of vaccine $x^{2}=1.89$, route of administration $x^{2}=1.11$, weight $x^{2}=2.13$, were not significant at the level of 0.05 .

It was inferred that there was no significant association between post test pain perception and selected demographic variables age, gender, education of father \& mother, occupation of father \& mother, income, number of children, birth order, religion, types of family, place of residence, types of vaccine, route of administration, weight of baby. So the administration of oral sucrose solution was independently effective in reducing pain perception among infants during immunization.

The fourth objective of the study was to find out the association between post test level of pain perception with selected demographic variables among control group infants

There is no association between the post test level of pain with selected demographic variables among control group infants.

\section{Recommendations}

1. The same study in larger group of homogenous members may be tried.

2. This study can be conducted by combining with other alternative therapy.

3. A comparative study can also be done between the effectiveness of various non-pharmacological measures on reducing pain perception among infants such as play therapy, breast feeding.

\section{Conclusion:-}

The administration of oral sucrose solution was effective in the reduction of pain perception among infants undergoing immunization injection. Majority $21(70 \%)$ of infants in experimental group experienced mild pain after administering oral sucrose solution, where as majority 29 (97\%) of the infants in control group had severe pain. So sucrose solution should be used as supportive therapy for reducing pain among infants undergoing immunization injection. 